\title{
Measles surveillance in Qatar, 2008: physicians' knowledge and practices and support received
}

\author{
Z.A. Nazzal, ${ }^{1}$ H. Said, ${ }^{7}$ N.A. Horeesh ${ }^{7}$ and S. Al-Attal ${ }^{1}$
}

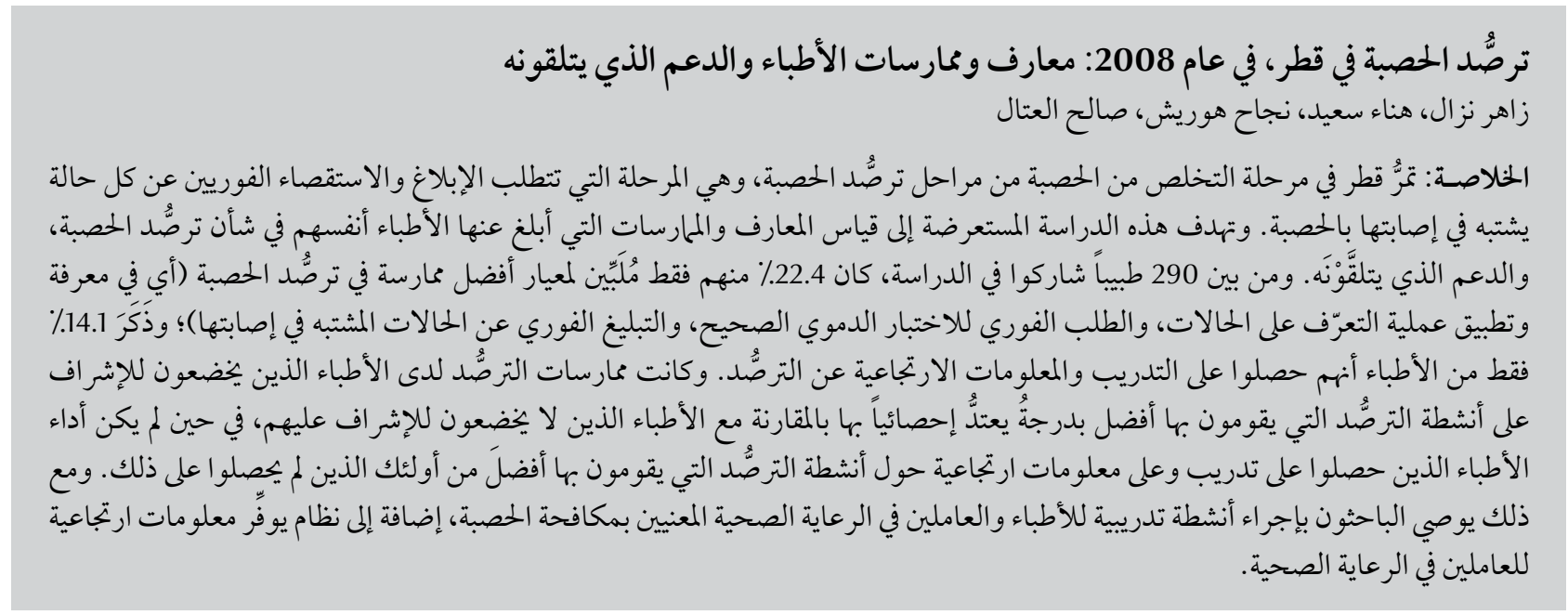

ABSTRACT Qatar is in the elimination phase of measles control which requires every suspected measles case to be notified and investigated immediately This cross-sectional study aimed to assess physicians' self-reported knowledge and practices concerning measles surveillance and the support they received. Of 290 physicians participating in the study, only $22.4 \%$ met the criterion for best practice in measles surveillance (i.e. knowing and applying the case definition and immediately ordering the correct blood test and immediately reporting suspected cases). Only $14.1 \%$ reported getting training and feedback on surveillance. Physicians supervised on their surveillance activities had significantly better surveillance practices than non-supervised physicians, whereas physicians who received training and feedback on their surveillance activities did not perform any better than those who did not. We recommend training activities for physicians and health care workers involved in the measles control as well a system of feedback to health care workers.

\section{Surveillance de la rougeole au Qatar en 2008 : connaissances et pratiques des médecins et soutien reçu}

RÉSUMÉ Le Qatar se trouve à la phase de l'élimination dams la lutte contre la rougeole, ce qui nécessite que chaque cas de rougeole suspecté soit notifié et immédiatement analysé. La présente étude transversale visait à évaluer les connaissances et les pratiques autodéclarées des médecins en matière de surveillance de la rougeole et le soutien qui leur était accordé. Sur 290 médecins participant à l'étude, seuls 22,4 \% satisfaisaient au critère de meilleures pratiques en matière de surveillance de la rougeole (c'est-à-dire connaître et appliquer la définition du cas, immédiatement demander l'analyse sanguine appropriée et immédiatement notifier les cas suspects). Seuls 14,1 \% indiquaient bénéficier d'une formation et d'un retour d'information sur leurs activités de surveillance. Les médecins bénéficiant d'une supervision en la matière avaient des pratiques nettement supérieures à celles des autres, alors que les médecins ayant participé à une formation et recevant un retour d'information dans ce domaine n'avaient pas de meilleurs résultats. Nous recommandons la mise en œuvre d'activités de formation pour les médecins et les agents de soins de santé impliqués dans la lutte antirougeoleuse ainsi qu'un système de rétro-information pour les agents de soins de santé. 


\section{Introduction}

Measles is the leading cause of vaccine preventable childhood mortality worldwide [1] and wastargetedfor elimination by 2010 in the Eastern Mediterranean Region [2]. Measles surveillance is one of the main strategies to achieve the goal of measles elimination [3]. It aims to ensure that most suspected measles cases are identified, correctly diagnosed and investigated, and complete information on reported cases is available for public health action $[4,5]$. Front-line health care workers (HCWs), mainly physicians, play a fundamental role in any effective epidemiological service, and their input is vital for strengthening surveillance systems [6].

Physicians' knowledge about disease notification affects their reporting practices $[7,8]$. Since surveillance is a systematic process, it requires that physicians know the correct details of all the surveillance steps and apply this knowledge precisely and accurately. Partial knowledge or inconsistent practices will be detrimental to the surveillance system. Hence, a well functioning measles surveillance programme requires, at minimum, knowledge about measles case definition and diagnostic blood testing, as well as appropriate application of this knowledge, in addition to timely notification of suspected measles cases. These elements can be collectively summarized in a single, composite variable that defines best practice in surveillance [9].

Support functions facilitate the implementation of the surveillance core functions. These include providing standards and guidelines (case definition, laboratory guidelines, outbreak investigation guidelines, etc.); training of personnel involved in the system; supervisory activities; communication facilities; providing resources (human, financial, logistics); monitoring and evaluation; and coordination [10]. It has been shown that availability of these support functions improves physicians' compliance and performance in surveillance of measles and other communicable diseases $[6,9,11-15]$.

Qatar is in the elimination phase of measles control according to $\mathrm{WHO}$; this requires that every suspected case be immediately notified to local health authorities and a blood specimen drawn to confirm the diagnosis through IgM blood level [16]. The aims of this study were to assess physicians' measles surveillance practices and to evaluate the surveillance support functions provided to physicians in Qatar.

\section{Methods}

\section{Setting and sample}

This cross-sectional study was conducted between January and February 2009, at Hamad Medical Corporation (HMC) facilities, primary health care (PHC) services and Qatar Petroleum (QP) health care services, i.e. the 3 main health care providers in Qatar. HMC is the main government provider of hospital care for all residents in Qatar free of charge. PHC is a government provider of primary care (and some secondary care) through 22 health care centres distributed across the country. QP is the largest oil company in Qatar, providing primary and secondary health care services to its workers and their families, about 200000 people. Ethical approval for the study was obtained from the research committee of HMC.

The studypopulation was physicians who were most likely to be in contact with cases of rash and fever diseases in Qatar, chiefly PHC physicians, paediatricians and accident and emergency physicians. The total number of eligible physicians was 744 . Sample size calculations, based on expected proportion of $50 \%$, a $95 \%$ confidence interval (CI) and a $5 \%$ absolute precision on either side of the proportion, indicated that the minimum required sample size was 254 physicians. This was inflated by $30 \%$ to compensate for the expected non- response rate. A proportionate stratified random sampling technique was employed to draw the required sample. Stratification was done based on type of health care facility.

\section{Data collection}

Qatar implements a primarily passive measles surveillance programme. The process starts when the treating physician suspects measles in a patient seeking health care. The treating physician should, as soon as possible, collect a specimen of blood and notify the case to the central surveillance unit in the communicable diseases department at the Supreme Council of Health where the responsible staff investigate the case and its contacts.

Data collection and analysis was conducted by the principle investigator. The director of each facility or department was approached to discuss the aims and objectives of the study and to ask their permission to conduct the study at their departments. The selected physicians were approached individually. Those who agreed to participate were given the questionnaire and asked to return it within 1 day. Those who did not reply in time were reminded once or twice, if needed.

A self-administered questionnaire, to be completed in English language, was used to collect data. It was adopted from the Centers for Disease Control and Prevention and WHO surveillance programme evaluation tools $[17,18]$ and was pre-tested with a convenience sample of 40 physicians of the study population to ensure clarity, time and ease of administration. The questionnaire included questions related to physicians' demographic characteristics; their knowledge and practices about measles surveillance; and the support they received for measles surveillance, such as training, supervision, feedback, availability of time, etc.

The WHO standard case definition is applied for measles surveillance in Qatar: "any person with fever and maculopapular rash and cough, coryza 
or conjunctivitis" or "any person in whom a physician suspects measles infection" [19].

The main study variables were physicians' knowledge of measles standard case definition, diagnostic testing, case notification and uses of surveillance data and practices relating to diagnosis and notification of suspected measles cases. Others were those related to support functions provided to physicians, such as supervision, training and feedback. Best practice in surveillance by physicians was defined as: applying the adopted case definition on suspected measles cases and immediately ordering the proper diagnostic test (IGM) and immediately reporting the suspected measles case [9].

\section{Data analysis}

The data were presented as percentages and medians with ranges. The chisquared or Fisher exact tests were used to compare between different proportions. A significance level of $P<0.05$ was considered to indicate statistical significant.

\section{Results}

A total of 290 physicians out of 365 completed and returned the questionnaire giving an overall response rate of $79.5 \%$. A majority of the physicians (73.5\%) were aged $30-49$ years, $61.0 \%$ were male and $83.1 \%$ were non-Qatari. Regarding facility, $41.4 \%$ of all physicians were working at PHC facilities, $25.9 \%$ at accident and emergency (A\&E) departments, $21.0 \%$ at HMC paediatric department, and $11.7 \%$ at QP health care centres (Table 1). Of the physicians $50.0 \%$ had 5 years or less experience at their current facility, $24.1 \%$ were residents in training and 35.5\% were clinical associates (Table 1).

\section{Physicians' knowledge and practice}

Of the physicians $90.7 \%$ correctly identified the standard measles case definition adopted in the surveillance system

\begin{tabular}{|c|c|c|}
\hline Characteristic & No. & $\%$ \\
\hline \multicolumn{3}{|l|}{ Workplace } \\
\hline PHC clinic & 120 & 41.4 \\
\hline A\&E department & 75 & 25.9 \\
\hline Paediatric department & 61 & 21.0 \\
\hline QP clinic & 34 & 11.7 \\
\hline \multicolumn{3}{|l|}{ Age (years) } \\
\hline$<30$ & 31 & 10.7 \\
\hline $30-39$ & 118 & 40.7 \\
\hline $40-49$ & 95 & 32.8 \\
\hline$\geq 50$ & 46 & 15.9 \\
\hline \multicolumn{3}{|l|}{ Sex } \\
\hline Male & 177 & 61.0 \\
\hline Female & 109 & 37.6 \\
\hline Missing data & 4 & 1.4 \\
\hline \multicolumn{3}{|l|}{ Job status } \\
\hline Resident & 70 & 24.1 \\
\hline Clinical associate & 103 & 35.5 \\
\hline Specialist/consultant & 116 & 40.0 \\
\hline Missing data & 1 & 0.4 \\
\hline \multicolumn{3}{|l|}{ Experience (years) } \\
\hline$\leq 5$ & 145 & 50.0 \\
\hline $6-15$ & 87 & 30.0 \\
\hline$>15$ & 39 & 13.4 \\
\hline Missing data & 19 & 6.6 \\
\hline \multicolumn{3}{|l|}{ Nationality } \\
\hline Qatari & 47 & 16.2 \\
\hline Non-Qatari & 241 & 83.1 \\
\hline Missing data & 2 & 0.7 \\
\hline
\end{tabular}

$P H C=$ primary health care; $A \& E=$ accident and emergency; $Q P=$ Qatar Petroleum . and $45.9 \%$ said that they always applied this case definition to their suspected patients (Table 2).

Almost all the physicians (97.2\%) said that they reported a measles case when they suspected it without waiting until it was confirmed and $85.1 \%$ knew that notification should be done on suspicion of a case without needing to wait until it is confirmed. However, only
Table 2 Physicians' responses to questions on knowledge and practices related to measles surveillance $(n=290)$

\begin{tabular}{lcc}
\hline Knowledge and practices & No. & $\%$ \\
$\begin{array}{l}\text { Correctly identified standard measles case definition } \\
\begin{array}{l}\text { Always apply standard case definition on their suspected } \\
\text { measles cases }\end{array}\end{array}$ & 263 & 90.7 \\
$\begin{array}{l}\text { Correctly identified measles recommended diagnostic } \\
\text { test (IgM) }\end{array}$ & 153 & 52.8 \\
$\begin{array}{l}\text { Immediately order a diagnostic test for their suspected } \\
\text { measles cases }\end{array}$ & 138 & 47.6 \\
\begin{tabular}{l} 
Notify a suspected measles case on the same day \\
\hline
\end{tabular} & 274 & 94.5 \\
\hline
\end{tabular}


$7.2 \%$ of all physicians could correctly identify the uses of collected surveillance data.

When asked about measles confirmatory laboratory testing, $52.8 \%$ of all surveyed physicians know the proper confirmatory test (IgM) and $47.6 \%$ of all physicians stated that they ordered it immediately. Concerning the time at which they reported it, $94.5 \%$ of physicians said that they notified it on the same day they saw the patient (Table 2).

\section{Physicians following best practice}

Only $22.4 \%$ of participating physicians followed all the criteria for best practice in surveillance (i.e. knowing and applying the case definition and immediately ordering the correct blood test and immediately reporting suspected cases). These proportions varied significantly by workplace, job status and years of work experience but not by sex or nationality (Table 3). The highest rate of best practice was among physicians in QP clinics (41.2), followed by paediatric departments (26.2\%) and PHC clinics (22.5\%), while physicians in A\&E departments had the lowest rate (10.7\%). The lowest proportion of physicians following best practice in surveillance was among residents and physicians with 5 or fewer years work experience at their current facility (15.2\% versus
$27.6 \%$ and $33.3 \%$ for more experienced practitioners). Similarly, resident physicians had lower rates of best practice (12.9\%) than clinical associates (23.2\%) or specialists/consultants (28.4\%).

\section{Support functions received}

With regard to support functions of the surveillance system, $80.7 \%$ never got feedback about reports they sent in, $14.1 \%$ got regular feedback and $5.2 \%$ did not answer the question. Only 13.8\% of physicians had been informed about the measles outbreaks that had occurred during the previous 2 years. On questions related to training and supervision, $14.1 \%$ of physicians had received local training on diseases surveillance and

\begin{tabular}{|c|c|c|c|c|c|}
\hline \multirow[t]{3}{*}{ Characteristic } & \multicolumn{4}{|c|}{ Followed best practice ${ }^{a}$} & \multirow[t]{3}{*}{$P$-value } \\
\hline & \multicolumn{2}{|c|}{ Yes } & \multicolumn{2}{|c|}{ No } & \\
\hline & No. & $\%$ & No. & $\%$ & \\
\hline Total & 65 & 22.4 & 225 & 77.6 & \\
\hline \multicolumn{6}{|l|}{ Facility } \\
\hline PHC clinic & 27 & 22.5 & 93 & 77.5 & \multirow{4}{*}{0.004} \\
\hline A\&E department & 8 & 10.7 & 67 & 89.3 & \\
\hline Paediatric department & 16 & 26.2 & 45 & 74.8 & \\
\hline QP clinic & 14 & 41.2 & 20 & 58.8 & \\
\hline \multicolumn{6}{|l|}{ Age (years) } \\
\hline$<30$ & 2 & 6.5 & 29 & 93.5 & \multirow{4}{*}{0.069} \\
\hline $30-39$ & 24 & 20.3 & 94 & 79.7 & \\
\hline $40-49$ & 26 & 27.4 & 69 & 72.6 & \\
\hline$\geq 50$ & 13 & 28.3 & 33 & 71.7 & \\
\hline \multicolumn{6}{|l|}{ Sex } \\
\hline Male & 43 & 24.3 & 134 & 75.7 & \multirow[t]{2}{*}{0.322} \\
\hline Female & 21 & 19.3 & 88 & 80.7 & \\
\hline \multicolumn{6}{|l|}{ Nationality } \\
\hline Qatari & 7 & 14.9 & 40 & 85.1 & \multirow{2}{*}{0.186} \\
\hline Non-Qatari & 57 & 23.7 & 184 & 76.3 & \\
\hline \multicolumn{6}{|l|}{ Job status } \\
\hline Resident & 9 & 12.9 & 61 & 87.1 & \multirow{3}{*}{0.048} \\
\hline Clinical associate & 23 & 23.2 & 80 & 77.7 & \\
\hline Specialist/consultant & 33 & 28.4 & 83 & 71.6 & \\
\hline \multicolumn{6}{|l|}{ Experience (years) } \\
\hline$\leq 5$ & 22 & 15.2 & 123 & 84.8 & \multirow{3}{*}{0.014} \\
\hline $6-15$ & 24 & 27.6 & 63 & 72.4 & \\
\hline$>15$ & 13 & 33.3 & 26 & 66.7 & \\
\hline
\end{tabular}

a Physicians who identify the correct case definition and apply it and immediately order the correct blood test and immediately report the suspected case. $P H C=$ primary health care; $A \& E=$ accident and emergency; $Q P=$ Qatar Petroleum. 


\begin{tabular}{l}
$\begin{array}{l}\text { Table 4 Physicians' responses to questions about surveillance support received } \\
(\boldsymbol{n}=\mathbf{2 9 0})\end{array}$ \\
\hline Item
\end{tabular}

only 5.9\% reported that they have been supervised on their surveillance activities. Notification forms were available at their facility for $95.2 \%$ of physicians, while the written standard measles case definition was available at facilities for $26.2 \%$ of physicians. Around threequarters of respondents (74.1\%) said that they always have enough time to notify a suspected measles case (Table 4).

Nearly half of all physicians supervised on their surveillance activities (47.1\%) followed best practice compared with only $20.9 \%$ among nonsupervised physicians $(P=0.012)$. On the other hand, physicians who received training and got feedback on their surveillance activities were no more likely to follow best practice than those who did not receive training/feedback ( $\mathrm{Ta}$ ble 5)

\section{Discussion}

The study presents for the first time data on measles best surveillance practice from a representative sample of all physicians seeing cases of childhood rash and fever in Qatar. The majority of the participants in this study were nonQatari (83.1\%), which is consistent with the demographics of the workforce in Qatar. Half of the participating physicians had experience of 5 years or less at their current facility because they were resident physicians who were relatively

\begin{tabular}{|c|c|c|c|c|c|}
\hline \multicolumn{6}{|c|}{$\begin{array}{l}\text { Table } 5 \text { Physicians following best practice in measles surveillance in relation to } \\
\text { surveillance support received }(n=290)\end{array}$} \\
\hline \multirow[t]{3}{*}{ Characteristic } & \multicolumn{4}{|c|}{ Followed best practice ${ }^{a}$} & \multirow[t]{3}{*}{$P$-value } \\
\hline & \multicolumn{2}{|c|}{ Yes } & \multicolumn{2}{|c|}{ No } & \\
\hline & No. & $\%$ & No. & $\%$ & \\
\hline \multicolumn{6}{|c|}{ Received feedback } \\
\hline Always & 3 & 50.0 & 3 & 50.0 & \\
\hline Sometimes & 5 & 13.9 & 31 & 86.1 & 0.126 \\
\hline Never & 52 & 21.9 & 185 & 78.1 & \\
\hline \multicolumn{6}{|c|}{ Received supervision } \\
\hline Yes & 8 & 47.1 & 9 & 52.9 & 0.012 \\
\hline No & 56 & 20.9 & 212 & 79.1 & \\
\hline \multicolumn{6}{|c|}{ Received training } \\
\hline Yes & 10 & 24.4 & 31 & 75.6 & 0.718 \\
\hline No & 54 & 21.9 & 193 & 78.1 & \\
\hline
\end{tabular}

aPhysicians who identify the correct case definition and apply it and immediately order the correct blood test and immediately report the suspected case. new graduates. Expansion of medical services in Qatar has necessitated hiring more doctors from outside the country.

Physicians' knowledge about measles case definition is a prerequisite for the best surveillance practice which maximizes the sensitivity and specificity of the system. The WHO recommended case definition for measles is adopted into routine surveillance in Qatar. This study shows that physicians were aware of the measles case definition; $90.7 \%$ of the participating physicians identified it correctly. However, only $45.9 \%$ of surveyed physicians stated that they always applied the adopted case definition. This divergence between knowledge and practice could be explained in 2 ways. The first is that physicians' knowledge was overestimated in this study as it was assessed via a self-administered questionnaire and physicians therefore had the opportunity to check the correct responses before returning the questionnaire. An alternative explanation is that not all knowledge is translated to practice; there is an intermediate linkattitudes - that can explain why people do not always act on their knowledge [20]. Either of these explanations could have played a role in the deficient practice observed, despite the good level of knowledge reported. In contrast, physicians' knowledge about the standard measles case definition reported in a study in Turkey [21] showed that PHC physicians were not fully aware (32\%) of the adopted measles case definitions, based on their measured practices rather than direct knowledge.

Countries conducting case-based measles surveillance are required to confirm the case diagnosis. WHO recommends that a blood sample is immediately drawn for each case for IgM testing [16]. In an accompanying paper we have reported on the timeliness of notification and completeness of measles surveillance data in a review of records at the same health facilities [22]. Our study showed that a discrepancy between what physicians said they did 
(47.6\% reported ordering the proper diagnostic test) and what was observed on the notification forms (20.9\% of the forms had information on blood specimen collection). This could indicate poor notification practices or an overestimation of practice on the questionnaire (because of bias in self-reporting) or it could be that the sample for this part of the study was not representative of all physicians [22].

Only $22.4 \%$ of the surveyed physicians followed all the criteria for best practice in surveillance. Interestingly, more QP physicians followed best practice than PHC physicians, even though PHC facilities were the first-line of contact with the health care system for a greater number of the population and we would expect the physicians there to have greater experience and knowledge about measles cases. This could be attributed to the lower workload in QP facilities compared with PHC facilities and $A \& E$ departments. On the other hand, $A \& E$ physicians had the lowest rate of best surveillance practice, which can be explained by emergency physicians being more concerned with trauma and emergency cases than rash and fever cases, which they may perceive as trivial cases.

Since the incidence of measles has been decreasing significantly and is in the elimination phase in most parts of the world, physicians nowadays, especially those more recently qualified, have a very low probability of encountering a measles case. This might be a factor in their surveillance practices, if physicians today are less likely to suspect measles than they did a few decades ago. This could be an explanation of our observed relationship between best surveillance practice and job status and experience, in which the lowest proportion of physicians with best surveillance practice was among residents and physicians with 5 or fewer years work experience at their current facility.

Surveillancesupportfunctionsareactivities that facilitate the implementation of the core functions of surveillance. The findings from this study indicated that the support functions, specifically feedback, supervision and training, were inadequately provided in Qatar.

Feedback, a major element in a surveillance system, was received by only $14.1 \%$ of the physicians and only $14.1 \%$ had been informed about measles outbreaks in the previous year. Studies showed that $40 \%$ and $33 \%$ of HCWs at PHCs in Germany [23] and in Nigeria [24] respectively received feedback on their surveillance data. These observations reflect a lack of emphasis by public health departments and health care facilities on surveillance support activities. This lack of emphasis might stem from a mistaken perception that such activities are not vital for a successful surveillance programme, or from a lack of adequate resources, human and otherwise, at the central level.

Training and supervision keeps physicians updated with standards and guidelines and motivates them to report notifiable infectious diseases. Only 5.9\% of the physicians in our survey were supervised on their surveillance activities and only $14.1 \%$ had received local training on disease surveillance. In contrast, Nsubuga et al. reported that in Tanzania $70 \%$ of health personnel had received some training in surveillance [25].

Physicians who were supervised on surveillance were significantly more likely to follow best practice in surveillance than those were not supervised, whereas training and feedback significantly did not affect physicians' best surveillance practice. These findings raise concerns about the quality and effectiveness of the current training and feedback activities in Qatar. Training activities and methods of feedback should be evaluated based on the best evidence, and effective systems should be adopted based on WHO recommendations and physicians' preferences.

In this study, $95.2 \%$ of the physicians confirmed the presence of copies of the notification forms at their facility. This is much higher than in a study conducted in the state of Vermont, United States, where $60 \%$ of the participating physicians claimed that notification forms were unavailable at their facility [26].

One of the limitations of this study was that the data collection method was a self-administered questionnaire and therefore some of the results, mainly knowledge items, could be overestimated as the physicians had the opportunity to check the answers before completing the questionnaire. This was explored by linking different knowledge items and linking knowledge with practice items, which revealed deficient physicians' practices that would have been overlooked otherwise. Moreover, physicians' actual quality of notification (in terms of completeness of data) was not evaluated, so there may have been reporting bias. It should also be cautioned that only univariate analysis was performed, so the possibility of confounding factors cannot be eliminated. However, our main aim was to address the proportion of physicians conducting proper surveillance and support functions provided to them.

\section{Conclusions and Recommendations}

This was the first report from Qatar concerning physicians' knowledge and practice on measles surveillance. It shows a fragmented knowledge and inconsistent practice; only $22.4 \%$ of the surveyed physicians were following best practice in measles surveillance, by applying the right case definition and immediately ordering the proper diagnostic test and reporting suspected cases. Furthermore measles surveillance support functions, such as supervision, training and feedback, were deficient. Based on these findings, we recommend strengthening the surveillance system nationwide through training activities 
for physicians to update their knowledge and improve their practices regarding disease notification. Better feedback systems must be developed, perhaps by allocating a focal person responsible for communicable diseases surveillance at the main health care facilities in Qatar to facilitate communication with the central level, ensure regular feedback to the health care providers, train and supervise employees and monitor and periodically evaluate the system.

\section{References}

1. Measles. Fact sheet no. 286. Geneva, World Health Organization, 2009 (http://www.who.int/mediacentre/factsheets/ fs286/en/, accessed 24 September 2011).

2. Guris D. Module on best practices for measles surveillance. Geneva, World Health Organization, 2001.

3. Khalil M et al. Measles in Saudi Arabia: from control to elimination. Annals of Saudi Medicine, 2005, 25:324-328.

4. Heath T et al. The National Measles Surveillance Strategy. Communicable Diseases Intelligence, 1999, 23(2).

5. World Health Organization. Global measles mortality reduction and regional elimination, 2000-2001 (part II). Weekly Epidemiological Record, 2002, 77:58-61.

6. Wahdan $\mathrm{MH}$. Epidemiological surveillance and its prospect in the region. Eastern Mediterranean Health Journal, 1999, 5:878-879.

7. AbdoolKarim S. Dilraj A. Reasons for under-reporting of notifiable conditions. South African Medical Journal, 1966, 86:834-836.

8. Friedman $\mathrm{S}$ et al. Suboptimal reporting of notifiable diseases in Canadian emergency departments: A survey of emergency physician knowledge, practices, and perceived barriers. Canada Communicable Disease Report, 2006, 32:187-198.

9. Field guidelines for measles elimination. Manila, World Health Organization Regional Office for the Western Pacific, 2004.

10. Pan American Health Organization. An integrated approach to communicable disease surveillance. Epidemiological Bulletin, 2000, 21(1)

11. Communicable disease surveillance and response systems: guide to monitoring and evaluating. Geneva, World Health Organization, 2006 (WHO/CDS/EPR/LYO/2006.2).

12. Hodge $M$, Haghgou $M$, Birmingham $M$. Making surveillance work. Module 3: Logistics management. Geneva, World Health Organization, 2001:22.

13. Fine $\mathrm{A}$, Layton $\mathrm{M}$. Lessons from the West Nile viral encephalitis outbreak in New York city, 1999: implications for bioterrorism preparedness. Clinical Infectious Diseases, 2001, 32:277-282.

14. Trepka M, Zhang G, Leguen A. An intervention to improve notifiable disease reporting using ambulatory clinics. Epidemiology and Infection, 2009, 137:22-29.
15. Kabore A, Perkins B, McDonnel S. Technical guidelines for integrated disease surveillance and response in the African region. Brazzaville, World Health Organization Regional Office for Africa, 2001.

16. Measles elimination field guide, 2nd ed. Washington, Pan American Health Organization, 2005.

17. Assessment of vaccine preventable disease surveillance system in Georgia. Report no. O28. Bethesda, Maryland, Ministry of Labor, Health and Social Affairs, and National Center for Diseases Prevention and Control, 2002.

18. Methodology for the multidisciplinary evaluation of the expanded program on immunization at the country level. Geneva, World Health Organization, 2000.

19. WHO-recommended standards for surveillance of selected vaccine-preventable diseases. Geneva, World Health Organization, 2003 (WHO/V\&B/03.01).

20. Figueirasa $A$ et al. Influence of physicians' attitudes on undernotifying infectious diseases: a longitudinal study. Public Health, 2004, 118:521-526.

21. Kurugöl $Z$ et al. The importance of laboratory confirmation in measles surveillance. Journal of Pediatric Infection (Çocuk Enfeksiyon Dergisi), 2007, 1:55-57.

22. Nazzal ZA et al. Measles surveillance in Qatar, 2008: quality of surveillance data and timeliness of notification. Eastern Mediterranean Health Journal, 2011, 17(11):813-817.

23. Krause G, Ropers G, Stark K. Notifiable disease surveillance and practicing physicians. Emerging Infectious Diseases, 2005, 11:442-445.

24. Bawa S, Olumide E, Umar U. The knowledge, attitude and practices of the reporting of notifiable diseases among health workers in Yobe State, Nigeria. African Journal of Medicine and Medical Sciences, 2003, 32:49-53.

25. Nsubuga $P$ et al. Structure and performance of infectious disease surveillance and response, United Republic of Tanzania, 1998. Bulletin of the World Health Organization, 2002, 80:196-203.

26. Schramm M, Vogt $R$, Mamolen $M$. The surveillance of communicable disease in Vermont: who reports? Public Health Reports, 1991, 106:95-97. 